\title{
Streshormone en fisieke aktiwiteit
}

Onnang 22 Januarie 1991; aanvaar 3 April 1991

\section{ABSTRACT}

\section{Stress hormones and physical activity}

Hormone secretion during physical activity of specific duration and intensity is part of the stress response. In a study to investigate the secretion of $\beta$-endorphin, leucine enkephalin and other recognised stress hormones during physical exercise, blood samples were taken from fourteen (14) healthy, male athletes who competed in a $21 \mathrm{~km}$ roadrace. Blood samples were collected before and after completion of the race. This study shows that $\beta$-endorphin/ß-lipotropin, leucine enkephalin, prolactin, and melatonin may be classified as stress hormones in physical activity of duration 80 to 120 minutes and intensity exceeding 75\%-VO $\mathrm{O}_{2}$ max. Widespread intra-individual variation in serum cortisol concentrations prevent definite conclusion. The unexpected increase in serum testosterone levels warrants further research.

Hormoonsekresie is die sine qua non van die stresrespons en onderlê die vele fisiologiese reaksies wat voorkom.

$\beta$-endorfien is 'n 31-aminosuurpolipeptiedhormoon van die adenohipofise en hipotalamus.' Dit is die endogene opioied wat in farmakologiese werkwyses en fisiologiese effekte die grootste ooreenkoms toon met morfien, die prototipe van die opioïedanalgetika. ${ }^{2}$

Vir baie dekades is morfien aangewend om hipofisefunksies te ondersoek. Kennis oor die hormonale effekte (invloed op liggaamstemperatuur, libido, menstruasie, urienvloei, vrystelling van kortikotropien en somatotropien) van die opioïedanalgetika dateer terug na die preëndorfientydperk. Dit wil voorkom asof $\beta$-endorfieneffekte, soos dié van morfien, op hipotalamusvlak uitgelok word. ${ }^{3}$

Leusienenkefalien is 'n pentapeptied wat onder meer wydverspreid in die brein, rugmurg en byniermedulla uit preproënkefalien en preprodinorfien gevorm word. 4. 5.6.7

Sedert die ontdekking van die opioiedpeptiede deur Hughes en Kosterlitz in 1975 het dit duidelik geword dat die endogene opioiede 'n magdom neuronale paaie en ekstraneurale teikenweefsels funksioneel betrek. ${ }^{3.8}$

Die endogene opiö̈ede kom in hoë konsentrasies voor in breingebiede wat o.a. by pyngeleiding en -persepsie, asemhaling, motoriese aktiwiteit, sekresie van hipofisehormone en gemoedstoestand betrokke is. Indien die endogene opioiede 'n komponent van die basiese sisteme uitmaak wat die reaksie op pyn en stres moduleer, is hierdie stowwe belangrik vir die gedrag, ervaring en emosionele respons teenoor die omgewing." 10

Fisiese aktiwiteit van spesifieke duur (15 tot 240 minute) en intensiteit $\left(\mathrm{VO}_{2}>75 \%-\mathrm{VO}_{2} \mathrm{max}\right)$ bevorder vrystelling van $\beta$-endorfien. 11. 12. 13, 14

In die literatuur is daar meningsverskil oor die vrystelling van enkefaliene tydens fisieke aktiwiteit. ${ }^{15}$

In 'n studie om die biologiese verband tussen $\beta$ endorfien, leusienenkefalien en ander erkende streshormone tydens fisieke aktiwiteit te ondersoek, is veertien (14) normaalgesonde, manlike atlete (ouderdomsgroep: 18 tot 45 jaar) vóór en ná aflê van 'n 21 km-wedloop (onder kompetisieomstandighede) ondersoek.

Bloedmonsters vir die bepaling van plasma- $\beta$-endorfienkonsentrasies is in silikoonbedekte glasbuise, wat EDTA bevat het, geneem. ${ }^{16.17}$ Bloedmonsters vir die bepaling van plasmaleusienenkefalienkonsentrasies is in silikoonbedekte glasbuise, wat EDTA en L-triptofaanhidroksamaat bevat het, geneem. ${ }^{18}$ Bloedmonsters vir dic bepaling van plasmamelatonienkonsentrasies is in litiumheparienbevattende glasbuise geneem. ${ }^{19}$

Opioiedpeptiede inhibeer die vrystelling van follitropien en lutropien deur inhibisie van dopamien- en/of noradrenaliensekresie deur adrenerge neurone van die mediane eminensie. ${ }^{24}$ Dit wil dus voorkom asof luliberiensekresie ook onder beheer van die endogene opioiede staan. Die produksie van spermatosoa en testishormone word onderskeidelik deur follitropien en lutropien bcheer. Lutropien werk op die interstisiële (Leydig)-selle in om sintese en sekresie van testosteroon te stimuleer. ${ }^{33}$ 'n Afname in testosteroonkonsentrasie sou dus gedurende verhoogde opioïedpeptiedkonsentrasie verwag kon word. Ons ondersoek ondersteun nie hierdie aanname nie, want 'n gemiddelde toename van $37,3 \%(20,6 \% ; 53,9 \%)$ in serumtestosteroonkonsentrasie het voorgekom.

Melatonien is 'n metoksie-indoolhormoon van die pineaalklier. ${ }^{34}$ Dit is 'n potente dopamienantagonis. ${ }^{35}$ Dus sal verhoogde melatonienkonsentrasies noodwendig lei tot verhoogde prolaktienkonsentrasies. 'n Toename in melatonien-, prolaktien- en kortisolsekresies tydens fisieke aktiwiteit van spesifieke duur en intensiteit $\left(\mathrm{VO}_{2}>60 \%-\mathrm{VO}_{2} \max \right)$ is reeds gerapporteer. ${ }^{36}$ Ons studie toon dat die fisieke aktiwiteit van sodanige tydsduur (80) tot 120 minute) en intensiteit $\left(\mathrm{VO}_{2}>75 \%-\mathrm{VO}_{2}\right.$ max $)$ was dat ' $n$ toename in $\beta$-endorfien/ $\beta$-lipotropien- en in melatonienkonsentrasies voorgekom het. Plasmamelatonienkonsentrasies het bykans versesvoudig (gemiddelde toename van $590,3 \%$ met $95 \%$-vertrouensinterval: $(487,3 \% ; 693,2 \%))$.

Hoewel die fiksheidsgraad van atlete nie vooraf bepaal is nie, mag die verdubbeling (gemiddelde toename van $234,6 \%$ met $95 \%$-vertrouensinterval: $(158,3 \% ; 310,8 \%))$ in plasmaleusienenkefalienkonsentrasies op 'n mate van onfiksheid dui. ${ }^{37}$

Uit die verkreë resultate (Tabel 1) wil dit voorkom of $\beta$ endorfien/ $\beta$-lipotropien, leusienenkefalien, prolaktien en melatonien sonder meer as streshormone tydens fisieke aktiwiteit geklassifiseer kan word. Die onverwagte toename in serumtestosteroonkonsentrasie vereis verdere ondersoek. 
TABEL 1

\section{Opsomming van resultate}

$(n=14)$

\begin{tabular}{|c|c|c|}
\hline $\begin{array}{l}\text { } \beta \text {-endorfien/ } \\
\beta \text {-lipotropien } \\
\text { (fmol.ml ') }\end{array}$ & VOOR & $13,9 \pm 3,3$ \\
\hline $\begin{array}{l}\text { Prolaktien } \\
\text { (mE.ml ') }\end{array}$ & $170,2 \pm 74,7$ & $368,1 \pm 266$ \\
\hline $\begin{array}{l}\text { Kortisol } \\
\text { (nmol.ml ') }\end{array}$ & $593,1 \pm 111,0$ & $644,9 \pm 336,7$ \\
\hline $\begin{array}{l}\text { Testosteroon } \\
\text { (nmol.ml ') }\end{array}$ & $21,9 \pm 5,5$ & $30,0 \pm 9,5$ \\
\hline $\begin{array}{l}\text { Melatonien } \\
\left(\mathrm{pg} \cdot \mathrm{ml}^{-1}\right)\end{array}$ & $11,8 \pm 6,7$ & $81,4 \pm 20,4$ \\
\hline $\begin{array}{l}\text { Leusienenkefalien } \\
\text { (fmol.ml ') }\end{array}$ & $5,6 \pm 2,4$ & $18,9 \pm 7,5$ \\
\hline
\end{tabular}

Bloedmonsters vir die bepaling van serumprolaktien-, -kortisol-, -testosteroonkonsentrasies en 'n biochemiese profiel is terselfdertyd geneem. Tyd, ouderdom, liggaamsmassa, polstempo en sistemiese bloeddruk is ook geneem.

'n Omkeerfase-vloeistofchromatografiesisteem met metanol as elueermiddel is vir ekstraksie van endogene opioïede gebruik. ${ }^{16}$ Plasma- $\beta$-endorfien/ $\beta$-lipotropien- en leusienenkefalienkonsentrasies is opvolgend gekwantifiseer deur poliklonale teenliggame teen onderskeidelik $\beta$ endorfien en leusienenkefalien in R.I.A.-prosedures aan te wend. ${ }^{20}$ Kruisreaktiwiteit van $\beta$-endorfien met $\beta$ lipotropien was $100 \% .^{21}$ Kruisreaktiwiteit van leusienenkefalien met metionienenkefalien was minder as $5 \% .22$

Plasmamelatonienkonsentrasies is, na ekstraksie, volgens die R.I.A.-metode van Brown bepaal. ${ }^{19}$. 23 Serumprolaktien-, -kortisol- en -testosteroonkonsentrasies, en biochemiese profiele is volgens standaardprosedures deur die Departement Chemiese Patologie, UOVS bepaal.
Uit die literatuur is dit bekend dat die endogene opioiede as moduleerders van sekresie van ander hormone optrec (kortikoliberien, prolaktien, somatotropien, en die gonadotropiene). ${ }^{324,25} \beta$-endorfien en kortikotropien word gelyktydig gesintetiseer en gesekreteer gedurende fisicke stres. So ook word metionienenkefalien en leusienenkefalien gelyktydig met die katecholamiene deur die byniermedulla gesekreteer. ${ }^{72}{ }^{26 .}{ }^{27 .}{ }^{28}$ Dit wil dus voorkom asof dic opioïedpeptiede nie net die sekresie van ander hormone moduleer nie, maar in eie reg 'n rol as streshormone mag speel.

$\beta$-endorfien inhibeer sekresie van dopamien deur dopaminerge neurone in die hipotalamus. 24. 25 Dopamien is die statien vir prolaktien. ${ }^{24.29}$ Verhoogde prolaktienkonsentrasies kan dus direk as gevolg van verhoogde $\beta$ endorfienkonsentrasies verwag word. Toename in beide vermelde hormone het dan ook tydens die marathonwedloop in atlete voorgekom. 'n Gemiddelde toename van $44,2 \%(95 \%$-vertrouensinterval: $17,4 \% ; 71,0 \%)$ in plasma$\beta$-endorfien/ $\beta$-lipotropien is aangetoon, terwyl serumprolaktienkonsentrasies meer as verdubbel het (gemiddelde toename van $116,4 \%$ met $95 \%$-vertrouensinterval: $41,7 \%$; $191,0 \%)$.

Die voorlopersubstans preproöpiomelanokortien gee oorsprong aan kortikotropien, $\alpha$-melanotropien en $\beta$ lipotropien. ${ }^{30,}{ }^{31}$ Laasgenoemde is die onmiddellike voorloper van $\beta$-endorfien. Die sintese van preproöpiomelanokortien word deur kortikoliberien gereguleer. ${ }^{32}$ Dit is bekend dat morfien kortikoliberiensekresie inhibeer. ${ }^{24}$ Daar is egter bewyse dat kortikotropien en $\beta$ endorfien nie noodwendig altyd in dieselfde verhouding gesintetiseer en gesekreteer word nie. ${ }^{30.31}$ 'n Toename in kortisol- en $\beta$-endorfien/ $\beta$-lipotropiensekresie kan dus tydens stres verwag word. Hoewel 'n gemiddelde toename van $8,7 \%(-26,5 \% ; 43,8 \%)$ aangetoon is, is dit uit die $95 \%$-vertrouensinterval duidelik dat wyduiteenlopende intraindiwiduele variasies in kortisolkonsentrasies voorgekom het. Dit bring mee dat geen definitiewe gevolgtrekking met betrekking tot kortisolkonsentrasieveranderinge gemaak kon word nie.

\section{E.H. de Wet* en J.M.C. Oosthuizen}

Departement Fisiologie, Universiteit van die Oranje-Vrystaat, Posbus 339, Bloemfontein 9300

\section{H.C. Barnard}

Departement Chemiese Patologie, Universiteit van die Oranje-Vrystaat, Posbus 339, Bloemfontein 9300

H.G. Luus

Departement Farmakologie, Universiteit van die Oranje-Vrystaat, Posbus 339, Bloemfontein 9300

\section{M.S. Bornman}

Roodeplaat Navorsingslaboratoriums, Pretoria, 0002

*Outeur aan wie korrespondensie gerig kan word.

\section{IITERATUURVERWYSINGS}

1. Zakarian. S. \& Smyth, D.G. (1982). Distribution of $\beta$-endorphinrelated peptides in rat pituilary and brain. Biochem $J, 202,561-71$.

2. Way, W. L. \& Way. E.L. (1987). In Basic and Clinical Pharmacology. Katzung, B.G. ed. (Appleton and Lange, Los Altos, California) p. 336-349.

3. Carr, D.B. \& Murphy, M.T. (1988). Operation, anesthesia, and the endorphin system, Int Anesthesiol Clin, 26(3), 199-205.
4. Zamir, N. et al. (1984). A dynorphinergic pathway of Leuenkephalin production in rat substantia nigra, Nature, 307, 643-5.

5. Elde, R. et al. (1976). Immunohistochemical studies using antibodies to leucine enkephalin: initial observations on the nervous system of the rat, Neuroscience, I, 349-51.

6. Hughes, J., Kosterlitz, H.W. \& Smith, T.W. (1977). The distribution of methionine-enkephalin and leucine-enkephalin in the brain and peripheral tissues, Br J Pharmacol, 61, 639-47.

7. Hughes, J. (1983). Biogenesis, release and inactivation of enkepha- 
lins and dynorphins. Br Med Bull, 39(1), 17-24.

8. Hughes, J. et al. (1975). Identification of iwo related pentapeptides from the brain with potent opiate agonist activity, Nature, 258, 577-9.

9. Barchas, J.D. et al. (1978). Behavioural neurochemistry: neuroregulators and behavioural states, Science. 200, 964-73.

10. Krieger, D.T. \& Martin, J.B. (1981). Brain peptides, Nen' Engl J Med, 304, 876-85.

11. Brooks, S. el al. (1988). The response of the catecholamines and betaendorphin to brief maximal exercise in man, Eur $I$ Appl Physiol, 57, 230-4.

12. Mougin, C. et al. (1987). Assessment of plasma opioid peptides, betaendorphin and met-enkephalin, at the end of an international ski race. Eur J Appl Phwsiol, 56, 281-6.

13. Oltras. C.M., Mora, M. \& Vives, F. (1987). Bela-endorphin and ACTH in plasma: effects of physical and psychological stress, Life Sci, 40, 1683-6.

14. Farrell, P.A. el al. (1987). Beta-endorphin and adrenocorticotropin response to supramaximal treadmill exercise in trained and untrained males, Acta Physiol Scand. 130, 619-62.5.

15. Farrel, P.A. el al. (1987) Enkephalins, catecholamines, and psychological mood alterations: effects of prolonged exercise, Med Sc Sports Exerc, 19, 347-353.

16. Hong, J-S., Yoshikawa, K. \& Hendren, R.W. (1983). Measurement of $\beta$-Endorphin en Enkephalins in Biological Tissues and Fluids, Methods Enzlimol, 103, 547-564.

17. Cahill, C.A.. Matthews, J.D. \& Akil, H. (1983). Human Plasma $\beta-$ Endorphin-like Peptides: A Rapid, High Recovery Extraction Technique and Validation of Radio inmunoassay. J Clin Endocrinol Metab. 56(50), 992-997.

18. Lotti, M. el al. (1986). Radio immunoassay of Leucine-Enkephalin, I Nuclear Med Allied Sci, 30(1), 51-55.

19. Oosthuizen, G.M. (1988). Plasmamelatomienkonsentrasies in vrouens met mammakarsinoom, Ph D-proefskrif, Universiteit van die OranjeVrystaat, Bloemfontein, p. 49.

20. Terenius. L. \& Nyberg, F. (1987). Opioid peptides in man - analy- tical aspects, Life Sci, 41, 805-8.

21. Voubiljel, Rodioimmunoassay of $\beta$-endorphim, (Amersham, UK)

22. Voubiljel. Radioimmunoassay of leacine enkephalin. (Amersham. UK).

23. Brown, G.M. et al. (1983) Application of immunologic techniques to the study of pincal indolcamines. Pineal Res Rev, 1, 207.

24. Hadley. M.E. (1988). In Endocrinology, Hadley, Mac E. (PrenticeHall International Inc., USA) p. 496-504

25. Copolov, D.L. (1985). Opiovid hiology: The next set of questions. Aust NZ J Med, 15, 98-106.

26. Khachaturian, H. et al. (1985). Anatomy of the CNS opioid systems, Trends Neurosci, 8, 111-119.

27. Joseph. S.A., Pilcher, W.H. \& Knigge, K.M. (1985). Anatomy of the corticotropin-releasing factor and opiomelanocortin systems of the brain, Fed Proc; 44, 100-7.

28. Hargreaves, K. et al. (1987), Corticotropin releasing lactor (CRF) produces analgesia in humans and rats, Brain Res, 422, 154-7.

29. Granner, D.K. (1988). In Harper's Biochemistry: Murray, R.K. et al. (Appleton and Lange, Los Altos, California) p. 487.

30. Nakanishi, S. et al. (1979). Nucleotide sequence of cloned cDNA for bovine corticotrophin- $\beta$-lipotropin precursor, Nature, 278, 423-7.

31. Smyth, D.G. (1983). $\beta$-endorphin and related peptides in pituitary, brain, pancreas, and antrum, $B r M e d B u l l, 39(1), 25-30$.

32. Granner, D.K. (1988). In Harper's Biochemistry, Murran, R.K. et al. (Appleton and Lange, Los Altos, California) p. 490-3.

33. Meyer, B.J. \& Meij, H.S. (1988). In Die fisiologiese basis ian geneeskunde. Meyer. B.J. red. (HAUM. Pretoria) p. 64.15.

34. Rodwell, V.W. (1988). In Harper's Biochemistry. Murray, R. K. et al. (Appleton and Lange, Los Altos. California) p. 313-4

35. Meyer, B.J. \& Meyer, A.C. (1988). In Die fisiologiese basis vam geneeskunde. Meyer, B.J. red. (HAUM, Pretoria) p. 63.12-63.13.

36. Oosthuizen, J.M.C. (1983). 'n Ondersock na die funksies van die pineaalklier wal die mens, D Med Sci-procfskrif, Universiteit van Pretoria, Pretoria. p. 47-76.

37. Slorzo, G.A. (1988). Opioids and exercise, Sports Med, 7, 109-124 